\title{
Do changes in iron metabolism contribute to the acceleration of the atherosclerosis process?
}

\author{
DOROTA FORMANOWICZ \\ Department of Clinical Biochemistry and Laboratory Medicine, Poznań University of Medical Sciences, Poland \\ e-mail: doforman@ump.edu.pl
}

\begin{abstract}
There are several risk factors whose association with atherosclerosis, a chronic disease with complicated etiology, is well established, including age, gender, smoking, lipids metabolism disorders, diabetes mellitus, obesity and reduced physical activity. Surprisingly, many cardiovascular related deaths occur in individuals without standard risk factors, so it has been suggested that these cases must be the result of other factors, previously not taken into account. This phenomenon resulted in the development of research focused on finding new risk factors. In 1981, Sullivan first postulated the so-called "iron hypothesis", suggesting that the regular menstrual iron loss, rather than other known effects of estrogen, protects women against coronary heart disease. It is widely believed at present, that iron is an essential catalyst in the oxidation and oxidative modification of low-density lipoprotein cholesterol which appears to be one of the pivotal steps in the early phase of the formation of the atherosclerotic plaque. Thus, iron depletion through menstrual loss might reduce oxidative stress and beneficially affect atherogenesis. Stored iron appears to be essential in the process of atherogenesis which is strictly required for normal cellular metabolism but also serves as a reservoir from which toxic-active iron can be liberated under atherogenic stimuli and result in lipid peroxidation. In this process, two pathways i.e., iron homeostasis metabolic pathway and metabolic pathways involving proinflammatory cytokines are closely interconnected. In human monocytes, these cytokines also increase the uptake of non-transferrin-bound iron, via the stimulation of divalent metal transporter-1 synthesis and cause iron retention by down-regulating ferroportin synthesis. It has been found recently that iron depositions are prominent in human atherosclerosis lesions. It can therefore be concluded that the results of scientific research, particularly those of the last ten years, provide a strong pathological basis to support the role of iron metabolism alterations in vascular damage and in the progression of atherosclerosis process.
\end{abstract}

Key words: iron, atherosclerosis, inflammation, oxidative stress

\section{Introduction}

Diseases associated with atherosclerosis, including cardiovascular disease (CVD) continue to be the leading cause of death in many countries. Yet, about 25 percent of CVD deaths in men and 15 percent in women occur in individuals with multivariate Framingham Study risk scores in the lowest two quintiles, according to standard risk factors (Meyers, 1996; Leaverton et al., 1987). It has been suggested that about half of atherosclerotic cases cannot be attributed to standard risk factors. This fact contributed to the development of research aimed at finding new factors, which would explain this phenomenon.

The presence of gender differences in the incidence and mortality from atherosclerosis-related disease is unquestionable in most population studies. The lower incidence of CVD in women has never been adequately ex- plained. Researchers began to look for the cause of this phenomenon. Clinical observations and experimental studies since 1950s (Siperstein et al., 1953) have suggested that body iron may be associated with atherosclerosis. In 1981, Sullivan first observed an increased risk of myocardial infarction in people with high serum ferritin concentrations and subsequently formulated a socalled "iron hypothesis" which claims that iron depletion or mild iron deficiency protects against ischemic heart disease (Sullivan, 1981). He argued that the differences in the incidence of heart diseases among men and women can be explained rather by differences in the level of iron stores than by the influence of estrogen (Sullivan, 1989; Sulivan, 1992; Sulivan, 2001; Sulivan, 2003; Sulivan, 2005; Sulivan, 2007). This statement has drawn the attention of scientists for the last 25 years (Danesh and Appleby, 1999; Wood, 2004; You and Wang, 2005) who 
have investigated the potential involvement of free iron in increasing the risk of heart diseases by supporting lipids peroxidation via catalysis of free radicals production (Heinecke, 1998; Reaven and Witztum, 1996).

The main aim of this work was to present the current state of knowledge on the involvement of iron in the process of atherosclerosis, with particular focus on the role of iron in signaling pathways in atherosclerosis.

\section{Atherosclerosis as an immune system-mediated inflammatory disease}

Our understanding of atherosclerosis has evolved beyond the view that the atherosclerotic lesions consist of a lifeless collection of lipid debris. Results of numerous studies confirm that atherosclerosis is driven by a chronic inflammatory process (Libby, 2002), within the arterial wall initiated mainly in response to endogenously modified structures, particularly oxidized lipoproteins, that stimulate both innate and adaptive immune responses, leading to further alteration of the vascular wall and promoting disease progression and complications (Mallat et al., 2009). The development of atherosclerotic lesions involves interactions between four major cell types, i.e. endothelial cells, smooth muscle cells, macrophages, and lymphocytes. Considering most of the factors that affect the process of atherosclerosis it can be concluded that its development is dependent on the balance between proinflammatory, anti-inflammatory, and anti-oxidative defense mechanisms (Scott, 2004). Hereafter, an overview of this complex process has been presented.

Free radicals, defined as reactive chemical species having a single unpaired electron in an outer orbit (Riley, 1994), are considered to play a casual role in the formation of atherosclerotic plaque (Schächinger and Zeiher, 2002). The majority of free radicals that damage biological systems are oxygen free radicals, more generally known as "reactive oxygen species" (ROS), such as the hydroxyl radical $\left({ }^{\circ} \mathrm{OH}\right)$, hydrogen peroxide $\left(\mathrm{H}_{2} \mathrm{O}_{2}\right)$, or superoxide anion $\left(\mathrm{O}_{2}^{--}\right)$(Meyers, 1996). ROS are mediators of vascular signal transduction but may provoke an oxidative stress when their levels exceed the cellular detoxifying capacity. ROS-mediated oxidative stress and inflammation is increasingly implicated in many cardiovascular disorders, including atherosclerosis. The unstable configuration of free radicals leads to energy being released through reactions with adjacent molecu- les, such as proteins, lipids, carbohydrates, and nucleic acids. Low-density lipoproteins (LDL) react with unstable free radicals and are modified into the oxidized form (ox-LDL). The small oxidized lipids that are components of ox-LDL, such as oxysterols, oxidized fatty acids, and aldehydes, are potent inducers of ROS production and further contribute to the severity of the oxidation process (Riley, 1994; Schächinger and Zeiher, 2002).

The ox-LDL particles involved in the formation of atherosclerotic plaque have been quite thoroughly investigated. It is well known that the modified LDL particles activate endothelial cells to synthesize monocyte chemotactic protein-1 (MCP-1). This protein attracts monocytes from the vessel lumen into the subendothelial space (Navab et al., 1991). Following the influx of monocytes, it reaches their maturation and transformation into macrophages. Macrophages are responsible for ox-LDL phagocytosis. After phagocytosis, via unregulated scavenger receptor-mediated endocytosis, lipoproteins are efficiently delivered to lysosomes where their degradation occurs (Brown and Goldstein, 1983). However, ox-LDL protein is partially resistant to lysosomal degradation and begins to accumulate within the macrophage lysosomes (Jessup and Kritharides, 2000). This accumulation is, at least partly, responsible for the transformation of macrophages into foam cells. This in turn leads to inflammatory responses (Galle et al., 2006) and induction of an apoptotic and/ or necrotic (Martinet and Kockx, 2001) process which represents a major cause of atherosclerotic plaque growth and its rupture (Schrijvers et al., 2007).

Moreover, atherosclerotic lesions are infiltrated by lymphocytes. Despite the fact that they contain both CD $8+$ and CD $4+$ T cells, CD 4 + memory $(C D 45 R O+)$ $\mathrm{T}$ cells predominate (Stemme et al., 1992). T cell adaptive immunity has long been thought of as only a promoter of proatherogenic immune response during atherosclerosis. The discovery of endogenous counter-regulators of the pathogenic immune response in atherosclerosis, particularly interleukin-10 (IL-10) and tumor growth factor- $\beta$ (TGF- $\beta$ ) led to the identification of an important role for regulatory $\mathrm{T}$ cells (Treg) in the control of atherosclerotic lesions development and/or their progression (Mach et al., 1999). Some researchers hypothesize that in the context of atherosclerosis, an imbalance exists between the pathogenic (Th1 and/or Th2) and regulatory $\mathrm{T}$ cells in response to 'altered' self antigens, leading to 
a reciprocal and mutual amplification of the innate and adaptive immune responses, responsible for plaque development and progression (Mallat et al., 2009).

\section{Iron and atherosclerosis}

\section{The unique properties of iron}

Iron metabolism is a very complex process. Detailed information about it has been presented, among others, in (Formanowicz D. et al., 2007; Sackmann A. et al., 2007; Sackmann A. et al., 2009; Formanowicz D. et al., 2011). Iron is required for a variety of normal cellular functions and is vital for proper growth and development. Some of these functions are well characterized, but others, especially those involved in the inflammatory process of atherosclerosis, are still less appreciated.

\section{The participation of iron}

\section{in iron-catalyzed Fenton reaction}

Iron has the ability to participate in the redox reactions by gaining access to several oxidation states (from $\mathrm{Fe}^{2+}$ to $\left.\mathrm{Fe}^{4+}\right)$. The transfer of one electron between the ferrous and the ferric ion is the essential redox chemistry in the acquisition, transport and storage of iron. Most iron present in humans is tightly complexed with proteins although some may be present as low molecularweight complex (LMW) in soluble pools (Harrison and Arrosio, 1996). The free iron is noxious to cells because it catalyzes the generation of hydroxyl radicals from superoxide and hydrogen peroxide (Rice-Evans and Burdon, 1993). Iron regulation in the humans ensures that there is no free intracellular iron; however, in vivo, under stress conditions, an excess of superoxide releases free iron from iron-containing molecules. The release of iron by superoxide has been demonstrated for $[4 \mathrm{Fe}-4 \mathrm{~S}]$ cluster-containing enzymes of the dehydratase-lyase family. Thus under stress conditions, $\mathrm{O}_{2}^{--}$acts as an oxidant of $[4 \mathrm{Fe}-4 \mathrm{~S}]$ cluster-containing enzymes and facilitates ${ }^{\circ} \mathrm{OH}$ production from $\mathrm{H}_{2} \mathrm{O}_{2}$.

The reaction of hydroxyl radicals generation is as follows:

$$
\mathrm{O}_{2}^{\cdot-}+\mathrm{H}_{2} \mathrm{O}_{2} \rightarrow \mathrm{O}_{2}+\mathrm{OH}^{-}+{ }^{\cdot} \mathrm{OH}
$$

It is catalyzed by iron ions:

$$
\begin{gathered}
\mathrm{Fe}^{2+}+\mathrm{H}_{2} \mathrm{O}_{2} \rightarrow \mathrm{Fe}^{3+}+\mathrm{OH}^{-}+{ }^{\cdot} \mathrm{OH} \\
\mathrm{O}_{2}^{--}+\mathrm{Fe}^{3+} \rightarrow \mathrm{O}_{2}+\mathrm{Fe}^{2+}
\end{gathered}
$$

These above-mentioned combinations of chemical reactions, known as the iron-catalyzed Haber-Weiss re- action or the superoxide-driven Fenton reaction, play an important role in the transformation of poorly reactive radicals into highly reactive ones. These highly reactive hydroxyl radicals can lead to DNA damage, impairment of normal protein synthesis and cell proliferation, and finally they may contribute to the endothelial dysfunction and atherosclerosis (Chau, 2000).

\section{The contribution of iron \\ in lipids peroxidation process}

It is well known that the metal-induced generation of ROS results in the attack on not just DNA in the cell nucleus, but also on other cellular macromolecules involving polyunsaturated fatty acid residues of phospholipids, which are extremely sensitive to oxidation (Umans and Levi, 1995). Iron reacts directly with unsaturated fatty acids or with preformed lipid hydroperoxides to form chain-carrying alkoxyl and peroxyl radicals, leading to severe damage of cellular integrity. The initiation of lipids peroxidation often depends on the occurrence of the ${ }^{\circ} \mathrm{OH}$ radical (Chau, 2000). Although, the ability of the ${ }^{\circ} \mathrm{OH}$ radical (generated via Fenton chemistry) to initiate lipids peroxidation is unquestionable, it is necessary to consider the diffusion-limited reactivity of this radical toward sugars, nucleotides, or proteins. The mechanism, proposed by Bucher and coworkers (Bucher et al., 1983) involves the formation of a $\mathrm{Fe}^{2+}: \mathrm{Fe}^{3+}$ complex (or a $\mathrm{Fe}^{2+} \mathrm{O}_{2}-\mathrm{Fe}^{3+}$ species) (Bucher et al., 1983). The maximal rates of lipid peroxidation were observed when the ratio of $\mathrm{Fe}^{2+}: \mathrm{Fe}^{3+}$ was $1: 1$. Bucher and coworkers also demonstrated that $\mathrm{ADP}-\mathrm{Fe}^{2+}$ promoted the peroxidation of phospholipid liposomes (Bucher et al., 1983). Moreover, several experimental models of iron overload, in vivo, revealed that mitochondrial polyunsaturated fatty acids (PUFA) are probably a preferential target for iron-driven peroxidation (Bacon et al., 1983; Valko et al., 2006).

\section{The effect of iron on nitric oxide metabolism}

Various iron complexes are involved in numerous steps of nitric oxide (NO) metabolism which has a direct impact on the atherosclerosis process. NO is an abundant reactive radical that works as an important oxidative biological signaling molecule in a large variety of physiological processes, including, for example, blood pressure regulation, smooth muscles relaxation and immune regulation (Umans and Levi, 1995; Radomski et 
al., 1987; Groves et al., 1995). Due to the wide spectrum of its activity, a fluctuation of physiological NO concentration contributes to a number of pathogeneses of several diseases. For example, a deficiency of NO synthesis plays a key role in atherosclerosis, hypertension, hyperglycemia, stroke, myocardial infarction, and ischemia. In fact, many physiological effects of $\mathrm{NO}$ are exerted as a result of its initial binding to $\mathrm{Fe}^{2+}$ - heme groups in the enzyme guanylate cyclase (Valko et al., 2006):

$$
\mathrm{Fe}^{2+}+\mathrm{NO}^{\bullet} \rightarrow \mathrm{Fe}^{2+}-\mathrm{NO}
$$

The active centre of NO synthase (NOS) contains an iron porphyrin complex with one thiolate axial ligand. Iron nitrosyls and nitrosothiols (Harrop et al., 2008) are the most relevant agents responsible for the storage and transport of NO and related compounds. Most of the target receptors of $\mathrm{NO}$ also contain iron centers and/or thiol groups. Nitrosothiols and metal nitrosylcomplexes are some of the most important external sources of NO. The most complex interactions between iron, NO and sulfur are observed in ternary iron-sulfur-nitrosyl systems. Most of these complexes contain diverse sulfur ligands. Depending on the nature of the bond, the ternary iron-sulfur-nitrosyl species may be classified into two groups, i.e. iron complexes with the S-nitrosothiol ligand, containing the (Fe-N(SR)O) moieties and RS-FeNO compounds, where both NO and sulfurs are coordinated to the Fe-centre (Szacilowski et al., 2005). Numerous studies have confirmed that the interactions of $\mathrm{NO}$ with iron, mainly derived from a cellular labile iron pool (LIP) and referred to as the redox-active iron pool or chelatable cellular iron (Yuan and Li, 2008; Pinero et al., 2000; Li et al., 2005; Kruszewski 2003), are enhanced and more likely during inflammation (Yuan and $\mathrm{Li}, 2008$ ). The co-localization of NO and iron has been shown in human atherosclerotic lesions (Kockx et al., 2003).

Moreover, both interferon- $\gamma$ (IFN- $\gamma$ ) and tumor necrosis factor- $\alpha$ (TNF- $\alpha$ ), cytokines involved in inflammatory-related atherosclerosis, induce the formation of nonheme $\mathrm{Fe}^{2+}$ nitrosyl thiol complexes (Yuan and Li, 2008). It was disclosed that in IFN- $\gamma$-activated macrophages NO may inhibit mitochondrial non-heme iron-dependent enzymes, by influencing iron at their Fe-S clusters (Szacilowski et al., 2005). The functions of these clusters, because of their sensitivity to oxidative stress and their redox potential, are not limited only to electron transfer, but also to the sensing of changes in $\mathrm{O}_{2}$ and iron. (Yuan and $\mathrm{Li}, 2008)$. Recent studies suggest that also adverse vascular effects of sulfur-containing homocysteine (an atherosclerosis risk factor) on the endothelial function are iron-dependant. It was found that some of the drugs, like for example iron sucrose, augment the homocysteine-induced endothelial dysfunction. This may suggest a potential link between intravenous iron and a cardiac risk (Zheng et al., 2006).

\section{The participation of iron in cooper, zinc, calcium and silicon metabolism}

Iron has the ability to participate in the metabolism of several metals, such as copper, zinc, calcium and silicon, which affects cellular homesostasis. This occurs as a result of the competition between these metals for the binding of transporters or iron-regulated enzymes. As an example, in vivo iron-copper interactions affect the distribution and content of iron. One of two feroxidases, which are the vital elements for maintaining iron homeostasis, is ceruloplasmin $(\mathrm{Cp})$ - a copper protein (Yuan and $\mathrm{Li}, 2008$ ). The expression of $C p$ gene is regulated by interleukin-1 (IL-1) (Di Patti et al., 2004), a proinflammatory cytokine, expressed mainly within the endothelium of atherosclerotic plaques and associated with the inflammatory mechanisms of atherogenesis (Dewberry et al., 2000).

\section{Iron affects the regulation of redox-sensitive transcription}

Many factors, including nuclear factor- $\mathrm{kB}$ (NF- $\mathrm{kB}$ ), activator protein-1 (AP-1), hypoxia-inducible factor-1 $\alpha$ (HIF-1 $\alpha$ ), early growth response-1 (Egr-1), and their related signaling pathways regulate the initiation and progression of the atherosclerotic plaque formation (Adhikari et al., 2006). Below the contribution of these factors to the process of atherosclerosis and their interaction with iron ions is presented.

$\mathrm{NF}-\mathrm{KB}$ is a transcriptional factor that plays an important role in redox reactions and in the inflammatory process during atherosclerosis. It mediates various biological events associated with atherosclerosis, including the production of inflammatory cytokines, the adhesion of monocytes on the endothelial cells, the proliferation, migration and apoptosis of smooth muscle cells, regulation of growth, division and differentiation of cells, apoptosis and cellular response to hypoxia and ischemia (Collins and Cybulsky, 2001). Furthermore, it was found that many common risk factors for atherosclerosis are 
also important activators of NF-kB. During the inflammatory process, heme derived iron plays a pivotal role in $\mathrm{NF}-\mathrm{KB}$ activation of macrophages. Lipopolisaccharide (LPS) promotes the secretion of proinflammatory cytokines in macrophages, which results in a rise in the concentration of intracellular LMW iron (LMWI) or nonheme iron. The LMWI response precedes NF- $\kappa \mathrm{B}$ activation and may be prevented by several iron chelators (Tsukamoto et al., 1999). The regulatory role of iron in the activation of NF-KB has been demonstrated in several diseases including atherosclerosis (Hoffmann et al.: Heinz Nixdorf Recall Study Investigative Group, 2007). The activation of NF- $\mathrm{kB}$ was found to be critical for the TNF- $\alpha$-induced inflammatory response, which is an important pathway in the atherosclerotic process. Addition of $\mathrm{Fe}^{2+}$ directly increases TNF- $\alpha$ release and TNF- $\alpha$ promoter activity in a NF- $\mathrm{kB}$ - dependent manner and leads to increased DNA binding of NF- $\kappa B$ subunits: p50/p50 and p65/p50 (She H.Y. et al., 2002). Furthermore, it was found that NF- $\mathrm{KB}$ is essential for the transcription of matrix metalloproteinase-10 (MMP-10) and matrix metalloproteinase-12 (MMP-12) genes, whose products are involved in extracellular matrix (ECM) remodeling and, potentially, in atherosclerotic plaque instability (Luttun et al., 2004). Increased transcription of these genes leads to the modulation of vascular permeability and remodeling, leukocyte transmigration and ECM integrity. These features are critical for the initiation, maintenance and resolution of atherosclerosis (Kempe et al., 2005).

AP-1 is a redox-sensitive transcription factor which is involved in the atherosclerosis process. It mediates gene regulation in response to a plethora of physiological and pathological stimuli, including cytokines, growth factors, stress signals, bacterial and viral infections, as well as oncogenic stimuli. Interactions between bioavailable iron and oxidative stress-responsive AP-1 have been assessed in genetic analyses and in experimental models. The presence of AP-1 transcription elements has been identified in the promoter region of the human hemochromatosis ( $H F E$ ) genes that are required for iron sensing. The activation of $A P-1$ was found to be copperdependent and a novel AP-1 site has been identified in the $\mathrm{Cp}$ gene. As already mentioned, $\mathrm{Cp}$ is involved in iron-cooper interactions. It was revealed that both hemin and ferric iron can induce and activate AP-1 (Masuya et al., 1999). Furthermore, it was discovered that the antioxidant/electrophile response element (ARE) on the human ferritin $\mathrm{H}$, responsible for the oxidant response, comprises two copies of AP-1 motifs. Mutations in each of AP-1 motifs impair protein binding and the function of the ARE, which is crucial for atherosclerosis (Tsuji, 2005).

Egr-1 is a nuclear protein which acts as a transcriptional regulator and is a major mediator of the cellular stress response. It was revealed that Egr-1 is significantly associated with plaque rupture and abnormal iron metabolism within macrophages in human carotid atherosclerotic lesions (Yuan and Li, 2008). Furthermore, recent studies have suggested that cellular iron status and Erg-1 may interact with each other in the pathogenesis of atherosclerosis. Egr-1 is a key transcriptional factor that mediates gene expression after vascular injury. Free heme, released from hemoglobin at the site of vascular injury or hemolysis, promotes ROS formation and LDL oxidation that are crucial for atherosclerosis. Egr-1, a major proatherogenic protein, is also induced by oxidative challenges, including oxidized lipids. So, Egr-1 is upregulated by ROS/oxidant stress (Hasan and Schafer, 2008).

HIF-1 is a transcriptional factor that responds to changes in available oxygen in the cellular environment. It is typically activated under hypoxic conditions but it can also be turned on by a number of non-hypoxic stimuli, including inflammatory signals such as $\mathrm{NO}$ and LPS. Upon activation the HIF- $1 \alpha /$ HIF- $1 \beta$ dimer binds to hypoxia response elements (HREs) in multiple genes, some of which play an important role during iron metabolism. They are: heme-oxygenase-1 (HO-1), transferrin receptor-1 (TfR1) (Tacchini et al., 2008), transferrin (Tf), erythropoietin (EPO) and $\mathrm{Cp}$. It should be noted that normoxic expression of HIF-1 $\alpha$ is essential for normal macrophage functions because their differentiation was found to be associated with LIP reduction and HIF induction (Yuan and Li, 2008). Moreover, ox-LDLs which are the key elements in the process of atherosclerosis induce HIF- $1 \alpha$ accumulation and HIF- $1 \alpha$ receptor activation in human macrophages via the redox-mediated pathway (Shatrov et al., 2003).

A summary of the transcription factors associated with iron metabolism, which affect the process of atherosclerosis, has been shown in the Table 1 . 
Table 1. Summary of the transcription factors associated with iron metabolism, which affect the process of atherosclerosis (adapted from Yuan and $\mathrm{Li}, 2008$ )

\begin{tabular}{|c|c|c|c|c|}
\hline $\begin{array}{c}\text { Name } \\
\text { of the factor }\end{array}$ & Function & $\begin{array}{l}\text { Regulators } \\
\text { related to iron }\end{array}$ & $\begin{array}{l}\text { Action in the iron } \\
\text { metabolism }\end{array}$ & Impact on atherosclerosis \\
\hline$N F-\kappa B$ & $\begin{array}{l}\text { control of immune and inflammatory } \\
\text { responses, developmental processes, } \\
\text { cellular growth, and apoptosis }\end{array}$ & $\begin{array}{c}\text { iron, deferoxamine } \\
\text { (DFO) }\end{array}$ & LIP & $\begin{array}{l}\text { expression } \\
\text { of atherosclerotic lesions, } \\
\text { plaque instability }\end{array}$ \\
\hline AP-1 & pro-inflammation & $\begin{array}{l}\text { cytokines, } \\
\text { redox status }\end{array}$ & $\begin{array}{l}\text { HFE, } \\
\text { ARE }\end{array}$ & vascular remodeling \\
\hline Egr-1 & $\begin{array}{l}\text { cell growth, development, } \\
\text { and stress responses }\end{array}$ & $\begin{array}{c}\text { iron, deferoxamine } \\
\text { (DFO) }\end{array}$ & cellular iron status & $\begin{array}{l}\text { vascular remodeling, } \\
\text { plaque development }\end{array}$ \\
\hline HIF-1 & hypoxia in inflammatory process & $\begin{array}{l}\text { iron, } \\
\text { ox-LDL }\end{array}$ & $\begin{array}{l}\text { HO-1, } \\
\text { TfR1, } \\
\text { Tf, } \\
\text { EPO, } \\
\text { Cp }\end{array}$ & $\begin{array}{l}\text { vascular remodeling, } \\
\text { coronary artery disease }\end{array}$ \\
\hline
\end{tabular}

Iron regulates the immune and inflammatory processes of atherosclerosis - interactions between inflammatory cytokines and iron-laden cells

The impact of iron on the immunological processes has been widely studied. It has been demonstrated that both iron deficiency and iron overload affect the function of $\mathrm{T}$ cells in immune response. Moreover, it was revealed that iron participates in the antigen presentation pathways. It may also counteract the effect of NO in T-cells (Yuan and Li, 2008). Inflammatory states are associated with changes in body iron homeostasis (Weiss, 2005). The main systemic response to inflammation is a decrease in plasma iron concentration accompanied by iron sequestration in the reticuloendothelial system. Prolonged hypoferremia occurring as a result of restricting iron availability for erythroid progenitor cells, may limit hemoglobin synthesis and cause an inflammation-related anemia (Ganz, 2003). Increased iron retention within the inflammatory macrophages, which is favored by the induction of body iron storage protein - ferritin and regarded as an attempt to withhold iron from the invading pathogens (Weiss, 2005) is caused by hepcidin-mediated down-regulation of the iron export protein ferroportin and a higher iron uptake (Formanowicz et al., 2007; Sackmann et al., 2007; Sackmann et al., 2009; Formanowicz et al., 2011).

The pathways of iron acquisition by macrophages are less clear, as are the changes induced by inflammatory stimuli. Studies on the HIF-1-mediated activation of gene expression of $T f R 1$ in macrophages show that by inducing NF- $\kappa$ B, inflammatory signals activate HIF-1-dependent and (IRP)-independent TfR 1 expression and the uptake of Tf-bound iron (Xiong et al., 2003). NF-kB activation, which is induced through the signaling cascade, dependent on toll-like receptor 4 (TLR4) - an important innate immune system activator, possibly involves a transient and early increase in the LMWI pool (Xiong et al., 2003). It occurs very early and leads to an increase in the activity of HIF-1 (Shatrov et al., 2003). The interactions between lymphocytes $\mathrm{T}$ and B/natural killer cells and TfR are well known (Seligman P.A. et al., 1991). They are dependent on Tf/TfR-mediated iron uptake while a blockade of this pathway leads to diminished proliferation and differentiation of these cells (Weiss G. et al., 1995).

Several autoantibodies and several inflammatory cytokines, such as IFN- $\gamma$, tumor TNF- $\alpha$, TGF- $\beta 1$ and interleukin-10 (IL-10) are associated with atherosclerosis and its manifestations. Earlier studies have confirmed the participation of iron-cytokines interactions in the course of inflammatory processes (Yuan and $\mathrm{Li}, 2008$ ). It was found, among others, that IL- 1 and TNF- $\alpha$ are responsible for the induction of iron uptake into monocytes/macrophages. Also, IFN- $\gamma$ and interleukin-2 (IL-2), by enhancing the TfR expression, affect the level of iron in monocytes/macrophages. Furthermore, LMWI, Tf-iron and heme-iron increase, and iron starvation decreases the production and activity of IFN- $\gamma$ and TNF- $\alpha$ (Brånén et al., 2004). 
Below we present the influences of cytokines and their interactions with iron in the process of atherosclerosis.

As it has been mentioned above, TNF- $\alpha$ is actively involved in the progression of atherosclerosis (Brånén et al., 2004). It regulates iron homeostasis by affecting the synthesis of key proteins such as: ferritin, Tf, TfR, and divalent metal transporter-1 (DMT-1), playing an important role in the iron metabolism. This cytokine mediates the low iron concentration during the inflammatory process and alters the ability of macrophages to handle cellular iron. Furthermore, iron-mediated ROS production and related pathways are directly influenced by TNF- $\alpha$ (Nanami et al., 2005). Besides, it has been found that macrophages from iron-loaded mice produce more TNF- $\alpha$ than the control group (Omara et al., 1994).

IFN- $\gamma$ is a crucial component of the innate immune respone. It modulates the uptake, release and storage of iron in monocytes/macrophages and increases the iron regulatory protein-1 (IRP-1) binding activity in macrophages (Kim and Ponka, 2000). Moreover, it increases the acquisition of non-Tf-bound iron by monocytes, partially by the stimulation of $D M T-1$ expression and it also retains iron inside the monocytes by inhibiting the synthesis of ferroportin and iron export (Ludwiczek et al., 2003). There is an inverse correlation between iron and the activity of the IFN- $\gamma$ signal pathways in macrophages (Ludwiczek et al., 2003).

Previous studies have shown that TGF- $\beta$ has an antiinflammatory and an atheroprotective effect and plays a crucial role in cardiovascular diseases. Interactions between TGF- $\beta$ and iron were disclosed in iron-overloaded animal model (rats were supplemented with iron, which lead to a significant accumulation of iron in their hepatic parenchyma) and in patients with a chronic renal failure after intravenous iron therapy (Gozdzikiewicz et al., 2006). TGF- $\beta$ inhibits the proliferation, activation, and differentiation of $\mathrm{T}$ cells toward $\mathrm{Th} 1$ and $\mathrm{Th} 2$. In addition, TGF- $\beta 1$ was found to maintain T-regulatory cells in the periphery of the thymus, by acting as a co-stimulatory factor for expression of Foxp3 gene involved in the immune system responses (Mallat et al., 2009; Taleb et al., 2008). It was also found that hepcidin plays important roles in iron metabolism via TGF- $\beta$ pathways. This factor positively regulates hepcidin gene expression through the so-called small mothers against decapenta- plegic homolog 4 (SMAD4) regulating hepcidin promoter activity (Yuan and Li, 2008).

The atherogenic role of IL-1 has been studied on the basis of several mice models of atherosclerosis (Yuan and $\mathrm{Li}, 2008$ ). It was revealed that chronic depletion of IL-1 affects lipoprotein metabolism and development of atherosclerotic lesions (Delvin et al., 2002). IL-1 may decrease the serum iron concentrations and increases the formation of iron-nitrosyl complexes (Uchida et al., 1991).

A summary of the above-presented iron-regulatory cytokines which affect the process of atherosclerosis, adapted from (Yuan and Li, 2008), has been shown in Table 2.

\section{Interactions of iron-binding and iron regulatory proteins in the development of atherosclerosis}

Iron metabolic pathways, including absorption, transport, distribution, storage, and reuse are achieved and regulated by several proteins. In the list of these proteins, Tf/TfR, ferritin, lactoferrin, hepcidin-ferroportin, cluster of differentiation 163 (CD-163), heme oxygenase1 (HO-1) and natural resistance-associated macrophage protein-1 (Nramp-1) have been implicated in the pathogenesis of atherosclerosis. General associations between these proteins and atherosclerosis have been presented below.

The concentrations of $\mathrm{Tf}$ and its receptor have been found to be significantly increased in the atherosclerotic intima (Yuan and $\mathrm{Li}, 2008$ ). It was observed that at $\mathrm{pH}$ 5.5 , Tf releases the transported iron. This $\mathrm{pH}$ promotes Tf-mediated low density lipoprotein oxidation by increasing iron release from $\mathrm{Tf}$ in atherosclerotic lesions. The latter may be a crucial step for in vivo LDL-oxidation (Lamb and Leake, 1994). As mentioned previously, many pro-inflamatory cytokines, i.e. IL-1, interleukin-6 (IL-6), TNF- $\alpha$ and IFN- $\gamma$ may influence the uptake of Tf and nonTf-bound iron in human monocytes.

The synthesis of ferritin ( $\mathrm{H}$ and $\mathrm{L}$ subunits) was found to be induced in vascular endothelial cells and macrophages of atherosclerotic lesions (Pang J.H. et al., 1996). Ferritin, whose principal role within cells is the storage of iron, was found to be associated with an increased risk of coronary artery disease and myocardial infarction (You and Wang, 2005). In a series of studies, Chau and colleagues (Pang et al., 1996; Lee et al., 1998; Lee et al., 1999a; Lee et al., 1999b) differentially scre- 
Table 2. Summary of the iron-regulatory cytokines which affect the process of atherosclerosis (adapted from Yuan and $\mathrm{Li}, 2008$ )

\begin{tabular}{c|l|l|l|l}
\hline $\begin{array}{c}\text { Name } \\
\text { of cytokine }\end{array}$ & \multicolumn{1}{|c|}{ Function } & $\begin{array}{l}\text { Regulators related } \\
\text { to iron }\end{array}$ & \multicolumn{1}{|c}{$\begin{array}{c}\text { Action in the iron } \\
\text { metabolism }\end{array}$} & \multicolumn{1}{c}{$\begin{array}{c}\text { Impact } \\
\text { on atherosclerosis }\end{array}$} \\
\hline TNF- $\alpha$ & $\begin{array}{l}\text { pro-inflammation } \\
\text { regulation of ROS, } \\
\text { apoptotic cell death induction }\end{array}$ & non-Tf-bound iron & $\begin{array}{l}\text { free iron, ferritin, TfR, } \\
\text { iron from [4Fe-4S] } \\
\text { increase }\end{array}$ & $\begin{array}{l}\text { formation of athero- } \\
\text { sclerotic lesions, } \\
\text { myocardial infarction }\end{array}$ \\
\hline IFN- $\gamma$ & $\begin{array}{l}\text { critical for innate and adaptive immu- } \\
\text { nity against viral and intracellular bac- } \\
\text { terial infections and for tumor control, } \\
\text { Jak-STAT pathway stimulation }\end{array}$ & DFO (suppression) & $\begin{array}{l}\text { iron (activation), } \\
\text { iron uptake } \\
\text { and release }\end{array}$ & $\begin{array}{l}\text { increase of T cells } \\
\text { and macrophages } \\
\text { in atherosclerotic } \\
\text { plaques }\end{array}$ \\
\hline TGF- $\beta$ & $\begin{array}{l}\text { anti-atherosclerosis, proliferation, cel- } \\
\text { lular differentiation control in most } \\
\text { cells, antiproliferative factor in normal } \\
\text { cells of epithelium }\end{array}$ & $\begin{array}{c}\text { iron (activation) } \\
\text { DFO (suppression) }\end{array}$ & $\begin{array}{l}\text { control of athero- } \\
\text { sclerotic lesion } \\
\text { development } \\
\text { and/or progression }\end{array}$ \\
\hline IL-1 & $\begin{array}{l}\text { pro-inflammation, central roles } \\
\text { in the regulation of the immune } \\
\text { responses }\end{array}$ & $\begin{array}{l}\text { iron-NO complex } \\
\text { (increase), } \\
\text { plasma iron (decrease) }\end{array}$ & $\begin{array}{l}\text { formation of athero- } \\
\text { sclerotic lesions }\end{array}$ \\
\hline
\end{tabular}

ened a cDNA library of human atherosclerotic aorta and discovered that genes for the iron-storage proteins, L-ferritin and H-ferritin, are highly expressed in human atherosclerotic plaques. In addition, Lapenna and coworkers (Lapenna et al., 2007) found a relationship between concentrations of serum ferritin and LMWI in ex vivo carotid endarterectomy specimens. They also found that LMWI correlates significantly with serum ferritin and reported an association of plaque LMWI with markers of lipids peroxidation in patients with <90\% stenosis of the arteries. These data are consistent with the possibility that the concentration of redox-active iron within atherosclerotic lesions can be lowered by depletion of body iron stores (Sulivan, 2007). Moreover, it was found that during the inflammatory response, cytokines are responsible for the transcriptional, posttranscriptional and translational regulation of ferritin levels and for its secretion (Torti and Torti, 2002). Thus, serum ferritin levels are increased by inflammation, suggesting that ferritin may modulate inflammation or immunity. Recently it has also been demonstrated (Coffman, et al., 2009; De Domenico et al., 2009) that this protein regulates blood vessel formation. The binding of ferritin to high molecular weight kininogen (HKa) inhibits HKa and promotes endothelial cells proliferation with consequent blood vessels formation and demonstrates a role for serum ferritin in cells proliferation (Lamb and Leake, 1994; Pang et al., 1996). Lactoferrin, an iron binding protein, bridges the innate and adaptive immune function. It acts as an antioxidant in iron-dependant oxidative stress, inhibits oxidative stress-induced apoptosis, and assists in the development of T-helper cell polarization (Yuan and Li, 2008; Kruzel et al., 2007).

A synthesis of human hepcidin, a hormone responsible for both, the regulation of absorption of dietary iron and iron release from macrophages and the mediation of innate immunity, is greatly stimulated by inflammation, hypoxia, iron and erythrophagocytosis (Delaby et al., 2005). It has been proposed that hepcidin, by preventing iron mobilization from macrophages in atherosclerotic lesions, plays an important role in atherosclerotic plaque destabilization (Knutson et al., 2005). However, previous studies in this field have given conflicting results (Yuan and Li, 2008; Oguz et al., 2006). Moreover, hepcidin was revealed to affect the development of atherosclerotic plaque by its function in immune response.

CD-163, the hemoglobin scavenger receptor, is also a scavenger receptor of monocytes/macrophages. It is responsible for hemoglobin binding and its internalization in the form of complexes with haptoglobin $(\mathrm{Hp})$ as well as for the prevention of oxidative and nitrosative toxicity by direct connection with hemoglobin (Yuan and $\mathrm{Li}$, 2008). After the endocytosis of hemoglobin:Hp complex, the heme subunit of hemoglobin is degraded by HO-1. Elevated synthesis of HO-1 and CD-163 correlates with 
Table 3. Summary of iron-binding and regulatory proteins which affect the process of atherosclerosis (adapted form Yuan and Li, 2008)

\begin{tabular}{|c|c|c|c|}
\hline $\begin{array}{l}\text { Name } \\
\text { of the protein }\end{array}$ & Function & Regulators & Impact on atherosclerosis \\
\hline $\mathrm{Tf}$ & $\begin{array}{l}\text { iron ions transporter, } \\
\text { acute phase protein }\end{array}$ & cytokines, inflammation & $\begin{array}{l}\text { LDL-oxidation, } \\
\text { atherosclerotic plaque instability }\end{array}$ \\
\hline Ferritin & $\begin{array}{l}\text { iron storage } \\
\text { acute phase protein }\end{array}$ & $\begin{array}{l}\text { cytokines, inflammation, } \\
7 \beta \text {-hydroxycholesterol ( } 7 \beta-\mathrm{OH}) \\
\text { - component of oxLDL }\end{array}$ & $\begin{array}{l}\text { atherosclerotic } \\
\text { plaque instability }\end{array}$ \\
\hline Hepcidin & $\begin{array}{l}\text { the master regulator of hu- } \\
\text { man iron homeostasis, inhi- } \\
\text { bits iron transport by } \\
\text { binding to the iron channel } \\
\text { - ferroportin }\end{array}$ & $\begin{array}{l}\text { cytokines, hypoxia, } \\
\text { inflammation, iron }\end{array}$ & $\begin{array}{l}\text { hepcidin-induced trapping of iron within } \\
\text { plaque macrophages may be } \\
\text { an important mechanism for promotion } \\
\text { of cardiovascular disease by systemic } \\
\text { inflammation }\end{array}$ \\
\hline CD-163 & $\begin{array}{l}\text { protection against oxidative } \\
\text { damage by mediating } \\
\text { the endocytosis of } \\
\text { haptoglobin - hemoglobin } \\
\text { complexes }\end{array}$ & cytokines & $\begin{array}{l}\text { erythrophagocytosis, } \\
\text { intraplaque hemorrhage }\end{array}$ \\
\hline HO-1 & $\begin{array}{l}\text { heme catabolism, iron } \\
\text { release from heme }\end{array}$ & oxidative stress, AP-1, NF-кB & $\begin{array}{l}\text { the protective role } \\
\text { against oxidative injury, }\end{array}$ \\
\hline Nramp-1 & divalent metal transporter & $7 \beta-\mathrm{OH}$ - component of oxLDL & lipid-induced apoptosis \\
\hline
\end{tabular}

the iron concentration in carotid atherosclerotic plaque (Ijäs et al., 2007).

HO-1 catabolizes cellular heme iron. The anti-atherosclerosis properties of HO-1 include: inducting adaptive responses against stimuli, scavenging ROS, reducing lipids peroxidation in plasma and artery wall, affecting cellular iron level and apoptosis, and protecting against ischemia/reperfusion injury (Perrella and Yet, 2003).

Nramps are responsible for the transport of divalent iron in a pH-dependant fashion. Except the intracellular divalent metal transport, they determine the macrophage functions in the immune and inflammatory processes. The ratio of TNF- $\alpha / \mathrm{IL}-10$ is controlled by Nramp- 1 and may create a balance between the apoptosis and macrophages survival (Rojas et al., 1999). It was discovered that an intense synthesis of Nramp-1 in macrophages of atherosclerotic plaque may be associated, among others, with the oxidized lipid-induced apoptosis in atherosclerosis (Li et al., 2004).

A summary of iron-binding and regulatory proteins which affect the process of atherosclerosis, adapted from (Yuan and Li, 2008), has been shown in Table 3.

\section{Conclusions}

Clinical observations and results of many experimental studies presented above confirm the participation of iron in the formation of atherosclerosis plaque.

Iron is likely involved in the development of atherosclerosis owing to its unique chemical properties, through its regulatory roles in the transcription process during inflammation and thanks to its regulatory roles in the function of pro-inflammatory cytokines. Moreover, it was revealed that iron likely participates in the atherosclerotic plaque formation through its interactions with regulatory proteins and iron-binding proteins. And finally, iron regulates the proliferation and development of $\mathrm{T}$ cells and the apoptosis of atheroma cells.

In summary, it can be argued that the participation of iron in the formation of atherosclerotic plaque is common. This link between iron and atherosclerosis is critical, especially for patients with iron metabolism disturbances and/or receiving iron due to chronic diseases such as anemia associated with a chronic kidney disease (CKD). It is known that patients suffering from CKD are characterized by intense atherosclerosis, which differs 
from its so-called classical form (Luczak et al., 2011). Perhaps one of the reasons of this situation is the coexistence of iron disturbances with impaired immune and inflammatory processes in these patients. One potential source of their oxidative stress is the "oversaturation" of transferrin induced by intravenous iron. The commonly used rapid infusion of iron leads to iron toxicity due to increased levels of unbound free iron, resulting in an increased peroxidation of cell and circulating lipids (Zanen et al., 1996). Whether in that case, the use of intravenous iron is a factor which exacerbates atherosclerosis in CKD patients remains an objective discussion.

\section{Acknowledgements}

This research has been partially supported by the Polish Ministry of Science and Higher Education grant no. N N 402 209833.

\section{References}

Adhikari N., Charles N., Lehmann U., Hall J.L. (2006) Transcription factor and kinase-mediated signaling in atherosclerosis and vascular injury. Curr. Atheroscler. Rep. 8: 252-260.

Bacon B.R., Tavill A.S., Brittenham G.M., Park C.H., Recknagel R.O. (1983) Hepatic lipid peroxidation in vivo in rats withchronic iron overload. J. Clin. Invest. 71: 429-439.

Brånén L., Hovgaard L., Nitulescu M., Bengtsson E., Nilsson J., Jovinge S. (2004) Inhibition of tumor necrosis factor-alpha reduces atherosclerosis in apolipoprotein $E$ knockout mice. Arterioscler. Thromb. Vasc. Biol. 24: 2137-2142.

Brown M.S., Goldstein J.L. (1983) Lipoprotein metabolism in the macrophage: implications for cholesterol deposition in atherosclerosis. Annu. Rev. Biochem. 52: 223-261.

Bucher J.R., Tien M., Aust S.D. (1983) The requirement for ferric in the initiation of lipid peroxidation by chelated ferrous iron. Biochem. Biophys. Res. Commun. 111: 777-784.

Chau L.-Y. (2000) Iron and atherosclerosis. Proc. Natl. Sci. Counc. ROC(B) 24: 151-155.

Coffman L.G., Parsonage D., D'Agostino R.Jr., Torti F.M., Torti S.V. (2009) Regulatory effects of ferritin on angiogenesis. Proc. Natl. Acad. Sci. USA 106: 570-575.

Collins T., Cybulsky M.I. (2001) NF-kappaB: Pivotal mediator or innocent bystander in atherogenesis? J. Clin. Invest. 107: 255-264.

Danesh J., Appleby P. (1999) Coronary heart disease and iron status: meta-analyses of prospective studies. Circulation 99: 852-854.

De Domenico I., McVey Ward D., Kaplan J. (2009) Serum ferritin regulates blood vessel formation: a role beyond iron storage. Proc. Natl. Acad. Sci. USA 106: 1683-1684.

Delaby C., Pilard N., Goncalves A.S., Beaumont C., Canonne-Hergaux F. (2005) Presence of the iron exporter ferroportin at the plasma membrane of macrophages is enhan- ced by iron loading and down-regulated by hepcidin. Blood 106: 3979-3984.

Delvin C.M., Kuriakose G., Hirsch E., Tabas I. (2002) Genetic alterations of interleukin-1 receptor antagonist in mice markedly affect non-HDL lipoprotein cholesterol levels and foam cell lesion size. Proc. Natl. Acad. Sci. USA 99: 6280-6285.

Dewberry R., Holden H., Crossman D., Francis S. (2000) Interleukin-1 receptor antagonist expression in human endothelial cells and atherosclerosis. Atheroscler. Thromb. Vasc. Biol. 20: 2394-2400.

Di Patti M.C., Persichini T., Mazzone V., Polticelli F., Colasanti M., Musci G. (2004) Interleukin-1beta up-regulates iron efflux in rat $\mathrm{C} 6$ glioma cells through modulation of ceruloplasmin and ferroportin-1 synthesis. Neurosci. Lett. 10: 182-186.

Formanowicz D., Sackmann A., Formanowicz P., Błażewicz J. (2007) Petri Net Based Model of The Body Iron Homeostasis. J. Biomed. Inform. 40: 476-485.

Formanowicz D., Sackmann A., Kozak A., Błażewicz J., Formanowicz P. (2011) Some aspects of anemia of chronic disorders modeled and analyzed by petri net based approach. Bioprocess. Biosyst. Eng. 34: 581-595. .

Galle J., Hansen-Hagge T., Wanner C., Seibold S. (2006) Impact of oxidized low density lipoprotein on vascular cells. Atherosclerosis 185: 219-226.

Ganz T. (2003) Hepcidin, a key regulator of iron metabolism and mediator of anemia of inflammation. Blood 102: 783-788.

Gozdzikiewicz J., Borawski J., Naumnik B., Rydzewska-Rosolowska A., Pawlak K., Mysliwiec M. (2006) TGF $\beta 1$ and endothelial/tissue injury with high-dose intravenous iron therapy in renal failure: evidence or perception? Clin. Appl. Thromb. Hemost. 12: 493-494.

Groves P.H., Banning A.P., Penny W.J., Newby A.C., Cheadle H.A., Lewis M.J. (1995) The effects of exogenous nitric oxide on smooth muscle cell proliferation following porcine carotid angioplasty. Cardiovasc. Res. 30: 87-96.

Harrison P.M., Arrosio P. (1996) The ferritins: molecular properties, iron storage function and cellular regulation. Biochim. Biophys. Acta. 1275: 161-203.

Harrop T.C, Tonzetich Z.J., Reisner E., Lippard S.J. (2008) Reactions of synthetic [2Fe-2S] and [4Fe-4S] clusters with nitric oxide and nitrosothiols. J. Am. Chem. Soc. 130: 15602-15610.

Hasan R.N., Schafer A.I. (2008) Hemin upregulates Egr-1 expression in vascular smooth muscle cells via reactive oxygen species ERK-1/2-Elk-1 and NF*B. Circ. Res. 102: 42-50.

Heinecke J.W. (1998) Oxidants and antioxidants in the pathogenesis of atherosclerosis: implications for the oxidized low density lipoprotein hypothesis. Atherosclerosis 141: 1-15.

Hoffmann B., Moebus S., Möhlenkamp S., Stang A., Lehmann N., Dragano N., Schmermund A., Memmesheimer M., Mann K., Erbel R., Jöckel K.H.: Heinz Nixdorf Recall Study Investigative Group (2007) Residential expo- 
sure to traffic is associated with coronary atherosclerosis. Circulation 116: 489-496.

Ijäs P., Nuotio K., Saksi J., Soinne L., Saimanen E., Karjalainen-Lindsberg M.-L., Salonen O., Sarna S., Tuimala J., Kovanen P.T., Kaste M., Lindsberg P.J. (2007) Microarray analysis reveals overexpression of $\mathrm{CD} 163$ and $\mathrm{HO}-1$ in symptomatic carotid plaques. Arterioscler. Thromb. Vasc. Biol. 27: 154-160.

Jessup W., Kritharides L. (2000) Metabolism of oxidized LDL by macrophages. Curr. Opin. Lipidol. 11: 473-481.

Kempe S., Kestler H., Lasar A., Wirth T. (2005) $N F \kappa B$ controls the global pro-inflammatory response in endothelial cells: evidence for the regulation of a pro-atherogenic program. Nucl. Acids Res. 33: 5308-5319.

Kim S., Ponka P. (2000) Effects of interferon- $\gamma$ and lipopolysaccharide on macrophage iron metabolism are mediated by nitric oxide-induced degradation of iron regulatory protein 2 .J. Biol. Chem. 275: 6220-6226.

Knutson M.D., Pukka M., Koss L.M., Aydemir F., Wessling-Resnick M. (2005) Iron release from macrophages after erythrophagocytosis is up-regulated by ferroportin 1 over expression and down-regulated by hepcidin. Proc. Natl. Acad. Sci. USA 102: 1324-1328.

Kockx M.M., Cromheeke K.M., Knaapen M.W., Bosmans J.M., De Meyer G.R., Herman A.G., Bult H. (2003) Phagocytosis and macrophage activation associated with hemorrhagic microvessels in human atherosclerosis. Atheroscler. Thromb. Vasc. Biol. 23: 440-446.

Kruszewski M. (2003) Labile iron pool: the main determinant of cellular response to oxidative stress. Mutat. Res. 531: 81-92.

Kruzel M.L., Actor J.K., Boldogh I., Zimecki M. (2007) Lactoferrin in health and disease. Post. Hig. Med. Dosw. 61: 261-267.

Lamb D.J., Leake D.S. (1994) Iron released from transferrin at acidic $\mathrm{pH}$ can catalyse the oxidation of low density lipoprotein. FEBS Lett. 352: 15-18.

Lapenna D., Pierdomenico S.D., Ciofani G., Ucchino S., Neri M., Giamberardino M.A., Cuccurullo F. (2007) Association of body iron stores with low molecular weight iron and oxidant damage of human atherosclerotic plaques. Free Radic. Biol. Med. 42: 492-498.

Leaverton P.E., Sorlie P.D., Kleinman J.C., Dannenberg A.L., Ingster-Moore L., Kannel W.B., Cornoni-Huntley J.C. (1987) Representativeness of the Framingham risk model for coronary heart disease mortality: a comparison with a national cohort study. J. Chronic. Dis. 40: 775-784.

Lee F.Y., Lee T.S., Pan C.C., Huang A.L., Chau L.Y. (1998) Colocalization of iron and ceroid in human atherosclerotic lesions. Atherosclerosis 138: 281-288.

Lee T.S., Shiao M.S., Pan C.C., Chau L.Y. (1999a) Iron-deficient diet reduces atherosclerotic lesions in apoE-deficient mice. Circulation 99: 1222-1229.

Lee T.S., Lee F.Y, Pang J.H, Chau L.Y. (1999b) Erythrophagocytosis and iron deposition in atherosclerotic lesions. Chin. J. Physiol. 42: 17-23.
Li W., Hellsten A., Nyhalah J.D., Yuan X.M. (2004) Enhanced expression of natural resistance-associated macrophage protein 1 in atherosclerotic lesions may be associated with oxidized lipid-induced apoptosis. Ann. N. Y. Acad. Sci. 1030: 202-207.

Li W., Hellsten A., Xu L.H., Zhuang D.M., Jansson K., Brunk U.T., Yuan X.M. (2005) Foam cell death induced by 7betahydroxycholesterol is mediated by labile iron-driven oxidative injury: mechanisms underlying induction of ferri tin in human atheroma. Free Radic. Biol. Med. 39: 864-875.

Libby P. (2002) Inflammation and atherosclerosis. Circulation 105: 1135-1143.

Luczak M., Formanowicz D., Pawliczak E., Wanic-Kossowska M., Wykretowicz A., Figlerowicz M. (2011) Chronic kidney disease-related atherosclerosis - proteomic studies of blood plasma. Proteome Sci. 9: 25.

Ludwiczek S., Aigner E., Theurl I., Weiss G. (2003) Cytokine mediated regulation of iron transport in human monocytic cells. Blood 101: 4148-4154.

Luttun A., Lutgens E., Manderveld A., Maris K., Collen D., Carmeliet P., Moons L. (2004) Loss of matrix metalloproteinase-9 or matrix metalloproteinase-12 protects apolipoprotein E-deficient mice against atherosclerotic media destruction but differentially affects plaque growth. Circulation 109: 1408-1414.

Mach F., Sauty A., Iarossi A.S., Sukhova G.K., Neote K., Libby P., Luster A.D. (1999) Differential expression of three Tymphocyte-activating CXC chemokines by human atheroma-associated cells. J. Clin. Invest. 104: 1041-1050.

Mallat Z., Taleb S., Ait-Oufella H., Tedgui A. (2009) The role of adaptive $T$ cell immunity in atherosclerosis. J. Lipid Res. 50: S364-S369.

Martinet W., Kockx M.M. (2001) Apoptosis in atherosclerosis: focus on oxidized lipids and inflammation. Curr. Opin. Lipidol. 12: 535-541.

Masuya Y., Kameshita I., Fujisawa H., Kohno H., Hioki K., Tokunaga R., Taketani S. (1999) MAP kinase-independent induction of proto-oncogene c-fos mRNA by hemin in human cells. Biochem. Biophys. Res. Commun. 260: 289-295.

Meyers D.G. (1996) The iron hypothesis - Does iron cause atherosclerosis? Clin. Cardiol. 19: 925-929.

Nanami M., Ookawara T., Otaki Y., Ito K., Moriguchi R., Miyagawa K., Hasuike Y., Izumi M., Eguchi H., Suzuki K., Nakanishi T. (2005) Tumor necrosis factor- $\alpha$ - induced iron sequestration and oxidative stress in human endothelial cells arterioscler. Thromb. Vasc. Biol. 25: 2495-2501.

Navab M., Imes S.S., Hama S.Y., Hough G.P., Ross L.A., Bork R.W., Valente A.J., Berliner J.A., Drinkwater D.C., Laks H. et al. (1991) Monocyte transmigration induced by modification of low density lipoprotein in cocultures of human aortic wall cells is due to induction of monocyte chemotactic protein 1 synthesis and is abolished by high density lipoprotein. J. Clin. Invest. 88: 2039-2046.

Oguz A., Uzunlulu M., Hekim N. (2006) Hepcidin is not a mar ker of chronic inflammation in atherosclerosis. Anadolu. Kardioyl. Derg. 6: 239-242. 
Omara F.O., Blakley B.R., Huang H.S. (1994) Effect of iron status on endotoxin-induced mortality, phagocytosis and interleukin-1 alpha and tumor necrosis factor-alpha production. Vet. Hum. Toxicol. 36: 423-428.

Pang J.H., Jiang M.J., Chen Y.L., Wang F.W., Wang D.L., Chu S.H., Chau L. (1996) Increased ferritin gene expression in atherosclerotic lesions. J. Clin. Invest. 97: 2204-2212.

Perrella M.A., Yet S.F. (2003) Role of heme oxygenase-1 in cardiovascular function. Curr. Pharm. Des. 9: 2479-2487.

Pinero D.J., Hu J., Cook B.M., Scaduto R.C., Connor J.R. (2000) Interleukin-1beta increases binding of the iron regulatory protein and the synthesis of ferritin by increasing the labile iron pool. Biochim. Biophys. Acta 1497: 279-288.

Radomski M.W., Palmer R.M.J., Moncada S. (1987) The role of nitric oxide and cGMP in platelet adhesion molecules to vascular endothelium. Biochem. Biophys. Res. Commun. 148: 1482-1489.

Reaven P.D., Witztum J.L. (1996) Oxidized low density lipoproteins in atherogenesis: role of dietary modification. Annu. Rev. Nutr. 16: 51-71.

Rice-Evans C., Burdon R. (1993) Free radical-lipid interactions and their pathological consequences. Prog. Lipid Res. 32: 71-110.

Riley P.A. (1994) Free radicals in biology: oxidative stress and the effects of ionizing radiation. Int. J. Radiat. Biol. 65: 27-33.

Rojas M., Olivier M., Gros P., Barrera L.F., Garcia L.F. (1999) $T N F-\alpha$ and IL-10 modulate the induction of apoptosis by virulent Mycobacterium tuberculosis in murine macrophages. J. Immunol. 162: 6122-6131.

Sackmann A., Formanowicz D., Formanowicz P., Koch I., Blazewicz J. (2007) An analysis of the Petri net based model of the human body homeostasis process. Computat. Biol. Chem. 31: 1-10.

Sackmann A., Formanowicz D., Formanowicz P., Błażewicz, J. (2009) New insights into the human body iron metabolism analysed by a Petri net based approach. Biosystems 96: 104-113.

Schächinger V., Zeiher A.M. (2002) Atherogenesis - recent insights into basic mechanisms and their clinical impact. Nephrol. Dial. Transplant. 17: 2055-2064.

Schrijvers D.M., De Meyer G.R.Y., Herman A.G., Martinet W. (2007) Phagocytosis in atherosclerosis: Molecular mechanisms and implications for plaque progression and stability. Cardiovasc. Res. 73: 470-480.

Scott J. (2004) Pathophysiology and biochemistry of cardiovascular disease. Curr. Opin. Genet. Develop. 14: 271-279.

Seligman, P.A, Kovar J., Schleicher R.B., Gelfand E.W. (1991). Transferrin-independent iron uptake supports B lymphocyte growth. Blood 15: 1526-1531.

Shatrov V.A., Sumbayev V.V., Zhou J., Brüne B. (2003) Oxidized low-density lipoprotein (oxLDL) triggers hypoxia-inducible factor-1 $\alpha$ (HIF-1 $\alpha$ ) accumulation via redox-dependent mechanisms. Blood 101: 4847-4849.

She H.Y., Xiong S., Lin M., Zandi E., Guilivi C., Tsukamoto H. (2002) Iron activates NF-kappaB in Kupffer cells. Am. J. Physiol. Gastrointest. Liver Physiol. 283: G719-726.
Siperstein M.D., Nichols C.W.Jr., Chaikoff I.L.L. (1953) Effects of ferric chloride and bile on plasma cholesterol and atherosclerosis in the cholesterol-fed bird. Science 117: 386-389.

Stemme S., Holm J., Hansson G.K. (1992) T lymphocytes in human atherosclerotic plaques are memory cells expressing CD45RO and the integrin VLA-1. Arterioscler. Thromb. 12: 206-211.

Sullivan J.L. (1981) Iron and the sex differences in heart disease risk. Lancet 1: 1293-1294.

Sullivan J.L. (1989) The iron paradigm of ischemic heart disease. Am. Heart. J. 117: 1177-1188.

Sulivan J.L. (1992) Stored iron and ischemic heart disease. Empirical support for a new paradigm (editorial comment). Circulation 86: 1036-1037.

Sulivan J.L. (2001) Misconceptions in the debate on the iron hypothesis. J. Nutr. Biochem. 12: 33-37.

Sulivan J.L. (2003) Are menstruating women protected from heart disease because of, or in spite of estrogen? Relevance to the iron hypothesis. Am. Heart. J. 145: 190-194.

Sulivan J.L. (2005) Stored iron and vascular reactivity. Atheroscler. Thromb. Vasc. Biol. 25: 1532-1535.

Sulivan J.L. (2007) Macrophage iron, hepcidin, and atherosclerotic plaque stability. Exp. Biol. Med. 232: 1014-1020.

Szacilowski K., Chmura A., Stasicka Z.(2005) Interplay between iron complexes, nitric oxide and sulfur ligands: Structure, (photo)reactivity and biological importance. Coord. Chem. Rev. 249: 2408-2436.

Tacchini L., Gammella E., De Ponti C., Recalcati S., Cairo G. (2008) Role of HIF-1 and NF-KB transcription factors in the modulation of transferrin receptor by inflammatory and anti-inflammatory signals. J. Biol. Chem. 283: 20674-20686.

Taleb S., Tedgui A., Mallat Z. (2008) Regulatory T-cell immunity and its relevance to atherosclerosis. J. Int. Med. 263: 489-499.

Torti F.M., Torti S.V. (2002) Regulation of ferritin genes and protein. Blood 99: 3505-3516.

Tsuji Y. (2005) JunD activates transcription of the human ferritin $H$ gene through an antioxidant response element during oxidative stress. Oncogene 24: 7567-7578.

Tsukamoto H., Lin M., Ohata M., Giulivi C., French S.W., Brittenham G. (1999) Iron primes hepatic macrophages for NF-kappaB activation in alcoholic liver injury. Am. J. Physiol. 277: G1240-1250.

Uchida T., Yamagiwa A., Nakamura K. (1991) The effect of interleukin-1 on iron metabolism in rats. Eur. J. Hematol. 46: $1-5$.

Umans J.G., Levi R. (1995) Nitric oxide in the regulation of blood flow and arterial pressure. Annu. Rev. Physiol. 57: 771-790.

Valko M., Rhodes C.J., Moncol J., Izakovic M., Mazur M. (2006) Free radicals, metals and antioxidants in oxidative stress-induced cancer. Chem. Biol. Interact. 160: 1-40.

Weiss G., Wachter H., Fuchs D. (1995) Linkage of cell mediated immunity to iron metabolism. Immunol. Today 16: 495-500. 
Weiss G. (2005) Modification of iron regulation by the inflammatory response. Best. Pract. Res. Clin. Haematol. 18: 183-201.

Wood R.J. (2004) The iron-heart disease connection: is it dead or just hiding? Ageing Res. Rev. 3: 355-367.

Xiong S., She H., Takeuchi H., Han B., Engelhardt J.F., Barton C.H., Zandi E., Giulivi C., Tsukamoto H. (2003) Signaling role of intracellular iron in $N F \kappa B$ activation. J. Biol. Chem. 278: 17646-17654.

You S.A., Wang Q. (2005) Ferritin in atherosclerosis. Clin. Chim. Acta. 357: 1-16.
Yuan X.-M., Li W. (2008) Iron involvement in multiple signaling pathways of atherosclerosis: a revisited hypothesis. Curr. Med. Chem. 15: 2157-2172.

Zanen A., Adriaansen H., Van Bommel E., Posthuma R., De Jong G.T. (1996) “Oversaturation” of transferrin after intravenous ferric gluconate (Ferrlecit) in hemodialysis patients. Nephrol. Dial Transplant. 11: 820-824.

Zheng H., Huang X., Zhang Q. (2006) Iron sucrose augments homocysteine-induced endothelial dysfunction in normal subjects. Kidney Int. 69: 642-644. 